\title{
EFEITOS DO ÁCIDO INDOLBUTÍRICO E DA ÉPOCA DE COLETA NO ENRAIZAMENTO DE ESTACAS DE GOIABEIRA (Psidium guajava L.) ${ }^{1}$
}

\author{
M. S. W. TAVARES ${ }^{2}$; E. KERSTEN"; F. SIEWERDT:" \\ 2 FAEM/UFPEL, C. P. 354, CEP: 96010-900, Pelotas, RS. \\ 3 Departamento de Fitotecnia da FAEM/UFPEL, C. P. 354, CEP: 96010-900, Pelotas, RS. \\ - IFMNTFELL, C. P. 354, CEP: 96010-900, Pelotas, RS.
}

RESUMO: Este trabalho fol desenvolvido com o objetivo de verificar o efelto de concentraçes de ácido indolbutírico (AIB) e da época de coleta sobre o enraizamento de estacas de golobeira (Psidium guajava L.), oriundas de plantas produtoras de frutos de polpa vermelha e de polpa branca, em estufa com nebullacho intermitente. Utilizou-se estacas apicais com um par de folhas e estacas medianas com dots pares de folhas, ambas cortadas pela metade. Após serem padronizadas em aproximadamente $15 \mathrm{~cm}$ de comprimento, proceleu-se ao tratamento introduzindo em torno de $1 \mathrm{~cm}$ da base da estaca em AIB na forma de p6, nas concentraçōes de zero, 4000, 5000, 6000 e 7000 ppm. Em seguida, colocouse o material em sacos de polletileno perfurado, contendo clnza de casca de arroz como substrato. As épocas de estaquia corresponderam aos meses de fevereiro, abril, julho e outubro de 1993. O delineamento experimental adotado fol o de blocos ao acaso, com 3 repetiçóes de 12 estacas por tratamento. Após 60 dias de permanência dentro da estufa, avaliouse a percentagem de estacas enraizadas, com calo, brotadas e peso de matéria seca das rázes. Nas condiçóes em que o trabalho foi realizado e de acordo com os resultados obtidos, verificou-se que a época de estaquia, infiuencla significativamente todas as variáveis estudadas. A malor média de estacas enraizadas ocorreu em fevereiro, com a estaca apical, onde obteve-se $51,52 \%$ de enraizamento. A brotacăo das estacas não cansou induçăo na formaçăo de raizes. Os tratamentos com o ácido indolbutírico (AIB), incrementaram o enraizamento e o peso de matéria seca de raizes das estacas de golabeira. Para as varívels brotaçăo e percentagem de estacas enralzadas, a variedade de polpa branca fol superior somente na quarta época, correspondente ao mês de outubro.

Descritores: estaquia, golabeira, AIB, ácido indolbutíricb. )

\section{EFFECTS OF INDOLEBUTIRIC ACID AND OF COLLECTION DATE ON THE ROOTING OF GUAVA CUTTINGS (Psidium guajava L.).}

SUMMARY - The purpose or this research work was to evaluate the effects of cutting collection date and of different concentrations of indolebutiric acid (IBA) on the rooting of apical and mid cuttings of guava (Psidium guajava L.). Two clones were used, one of white lesh and another of red Iesh fruits. The cuttings were collected from the trees at four times: February, April, June and October of 1993. Apical cuttings with two lenves and mid part branch cuttings with four halfeaves, both $15 \mathrm{~cm}$ long, were treated with 0,4000,5000, 6000 or $7000 \mathrm{ppm}$ of IBA as a powder mixture, introducing $1 \mathrm{~cm}$ of their basal end in the mixture containing IBA. After treatement the cuttings were planted in plastic bags containg ash of rice husk as substrate and kept in greenhouse under mist conditions. The experimental design was of randomized complete block with three replications and 12 cuttings per plot. After a 60 day period the cuttings were evaluated for the percentage of rooted cuttings, with calus, with new leaves and root dry welght per cutting. The date of cutting had significant efiects on all data. The highest percentage of rooted cutting $(51,52 \%)$ was observed on cuttings collected in February. Sprouting did not affect rooting. IBA treatments only increased dry weight of roots per cutting and percentage of rooting. There was a difference between the two clones with respect to the percentage of rooted cuttings and of sprouting, that were higher for the white fesh clone than for the red nesh clone, for the cuttings collected in October.

Key words: cuttings, guava, IBA, indolbitiric acid. ! .

1 Parte da dissertaçăo apresentada pelo primeiro autor para obtenção de Mestre em Agronomia/UFPEL.

5 Bolsista do CNPq.

Sci. agric., Piracicaba, 52(2):310-317, mai./ago. 1995 


\section{INTRODUÇĀO}

A goiabeira (Psidium guajava L.) é uma espécie frutifera pertencente à familia Myrtaceae que, embora seja nativa dos trópicos, é cultivada desde o Acre até o Rio Grande do Sul, embora de forma ainda extrativa em várias regiôes (MEDINA, 1988).

$O$ Brasil $\varepsilon$ o terceiro maior produtor mundial de goiaba, o Estado de São Paulo é o primeiro e - Rio Grande do Sul é o quarto do pais, com uma produção de 4 a 6 mil toneladas de frutas, praticamente toda para indústria (ANUÁRIO ESTATÍSTICO DO BRASIL, 1991).

Esta fruteira pode ser propagada pelos processos sexual e assexual. Mas apesar da facilidade e velocidade de obtenção de mudas, a propagação através de sementes, com finalidade de comercialização, não é recomendada devido a alta heterogeneidade desta espécie. Embora tenha uma taxa de autofecundação significativamente maior do que a da fecundação cruzada, sua propagação por sementes resultantes da polinização natural, origina descendentes com grande variação quanto a forma, hábito de crescimento e estatura de plantas e a produtividade e características dos frutos. Os pomares de goiabeira das principais regiōes produtoras da grande maioria dos Estados brasileiros, são formados por plantas oriundas de sementes. Mas alguns Estados, já vêm desenvolvendo trabalhos de pesquisa no sentido de introduzir, selecionar, propagar e difundir plantas de comprovada qualidade agronômica (MEDINA, 1988; GONZAGA NETO \& SOARES, 1994).

Existem inúmeras variedades fixadas de goiabeira nos diversos países produtores, porém, no Brasil, quase nada foi feito neste sentido, sendo que as "variedades" utilizadas são em sua maioria originárias de seleções locais (MEDINA, 1988). Segundo HAMILTON \& SEAGRAVE-SMITH (1954), incorretamente são denominadas "variedades", grupos de plantas que possuem nomes apenas descritivos $e$ são propagadas por sementes.

O presente trabalho teve por objetivo verificar o efeito do ácido indolbutírico e da época de estaquia sobre o enraizamento de estacas apicais e medianas de plantas produtoras de frutos com polpa de coloração vermelha e de coloração branca, em estufa com nebulização intermitente.

\section{MATERIAIS E METODOS}

O presente trabalho foi realizado em estufa de vidro com nebulizaçăo intermitente computadorizada, pertencente ao Departamento de Fitotecnia da FAEM/UFPEL, localizado no Campus Universitário, município de Capão do Leão, RS.

Trabalhou-se com dois grandes grupos de goiabeiras existentes na regiăo, quais sejam: grupo de plantas com frutos de polpa branca e grupo de plantas com frutos de polpa vermelha. Não há variedade identificada pois as árvores, originadas de sementes, apresentam uma grande diversidade de formas e cores de polpa dos frutos.

Em todas as épocas utilizou-se dois tipos de estaca: apicais e medianas. As estacas apicais foram preparadas, cortando-se o meristema apical abaixo das duas últimas gemas da extremidade do ramo e deixando-se um par de folhas, cortadas pela metade. Já as estacas medianas, foram retiradas da parte intermediária do ramo deixando-se dois pares de folhas, igualmente cortadas pela metade. Ambos tipos de estacas foram cortadas transversalmente na base, em bisel na extremidade.

Após serem padronizadas em aproximadamente $15 \mathrm{~cm}$ de comprimento, procedeu-se ao tratamento com AIB na forma de pó, nas concentraçães de $0,4000,5000,6000$ e $7000 \mathrm{ppm}$. Após, as estacas eram imediatamente colocadas em saquinhos de polietileno perfurados, contendo cinza de casca de arroz como substrato. Dentro de cada saquinho foram colocadas 3 estacas, perfazendo um total de 36 estacas por tratamento.

Ao longo de cada época de estaquia, procedeu-se semanalmente a aplicaçăo de fungicida a base de Captan, na concentração de $0,6 \%$, sobre o material vegetal.

As épocas de estaquia corresponderam aos meses de fevereiro, abril, julho e outubro de 1993. Em todas as épocas as estacas permaneceram por 60 dias dentro da estufa.

Os fatores estudados foram concentraçőes de $\mathrm{AIB}$, variedade de plantas, época e tipo de estaca. Ao final de cada época avaliou-se a percentagem de estacas enraizadas, com calo, brotadas e peso de matéria seca das raizes. $O$ delineamento experimental adotado foi o de blocos ao acaso, com 3 repetiçóes de 12 estacas por parcela.

\section{RESULTADOS E DISCUSSÃO}

\section{Percentagem de estacas enraizadas}

Os fatores época, tipo de estaca, tratamentos com AIB e a interação entre época e variedade foram significativos pelo teste $F$. 
TABELA 1. Percentagem média de estacas enraizadas dentro do fator variedade (cor da polpa), nas diferentes épocas de estaquia.

\begin{tabular}{lllll}
\hline \hline Variedade & Época 1 & Época 2 & Época 3 & Época 4 \\
\hline polpa vermelha & $49,62 \mathrm{aA}$ & $5,79 \mathrm{aB}$ & $0,01 \mathrm{aC}$ & $3,50 \mathrm{aB}$ \\
polpa branca & $41,14 \mathrm{aA}$ & $1,90 \mathrm{bC}$ & $0,01 \mathrm{aD}$ & $10,05 \mathrm{bD}$ \\
\hline \hline
\end{tabular}

Médias seguidas por letras distintas, minúscula na vertical e maiúscula na horizontal, diferem entre si pelo teste de Duncan ao nivel de $1 \%$ de probabilidade.

Pelo desdobramento da interação época $x$ variedade, TABELA 1 , verifica-se que houve variação de enraizamento dentro daqueles fatores. Com referência ao comportamento da variedade de polpa vermelha, o maior enraizamento de estacas ocorreu na época 1 , com $49,62 \%$ de enraizamento, correspondente à época de implantação fevereiro. Nesta época, com exceção da testemunha, os tratamentos com AIB tiveram médias muito próximas. A seguir, as épocas 2 (abril) e 4 (outubro), resultaram respectivamente em $5,79 \%$ e $3,50 \%$ de enraizamento, não diferindo significativamente entre si. A pequena média referente à época de implantação julho $(0,01 \%)$ é devido a ter enraizado apenas 2 estacas.

Para a variedade de polpa branca também a época de estaquia fevereiro foi a que resultou em maior enraizamento $(41,14 \%)$, seguida das épocas 4(outubro) e 2(abril). Nenhuma estaca desta variedade enraizou na época 3 (julho).

PEREIRA et al. (1991) constataram entre duas cultivares de goiabeira de polpa vermelha, Rica e Paluma, ter esta maior eficiência de enraizamento que a primeira, e ainda que a aplicação de AIB aumentou o potencial de enraizamento das duas cultivares.

O maior enraizamento das estacas coletadas em fevereiro, pode ser devido à qualidade dos ramos crescidos a partir da poda de inverno. $\mathrm{CA}$ -
VALCANTE (1993), afirma ser fevereiro e março os melhores meses para realizar a estaquia em todo país. FIGUEIREDO (1993), em trabalho realizado com goiabeira serrana, obteve a maior percentagem de estacas enraizadas, calo e sobreviventes na época de estaquia correspondente ao mês de março. NACHTIGAL (1994) ao trabalhar com araçazeiro, não constatou nenhuma variação de enraizamento quando as estacas são coletadas em janeiro ou março.

O potencial de enraizamento, pode ter sido também influenciado pela temperatura pois conforme HANSEN (1989), temperaturas em torno de $24^{\circ} \mathrm{C}$ estimula a divisão celular na área de enraizamento. No presente trabalho as temperaturas atingiram valores em torno de $30^{\circ} \mathrm{C}$ na época de maior enraizamento das estacas. A estação de verão acarreta também um aumento de horas de luz. Estacas semilenhosas e herbáceas, em presença de maior tempo de luz, são favorecidas por maior formação de fotossintetizados.

A maior percentagem de estacas enraizadas foi da apical (TABELA 2) e também, embora sem diferença significativa, foi a que mostrou melhores respostas ao AIB. Isto confirma a afirmação de HANSON (1978), de que estacas com baixo grau de lignificação respondem melhor ao tratamento com AIB.

TABELA 2. Percentagem média de estacas enraizadas dentro do fator tipo de estaca, nas diferentes épocas de estaquia.

\begin{tabular}{lllll}
\hline \hline Tipo de Estaca & Época 1 & Época 2 & Época 3 & Época 4 \\
\hline apical & $51,51 \mathrm{aA}$ & $3,95 \mathrm{aB}$ & $0,07 \mathrm{aC}$ & $8,34 \mathrm{aB}$ \\
mediana & $36,28 \mathrm{bA}$ & $3,25 \mathrm{aB}$ & $0,00 \mathrm{aC}$ & $4,65 \mathrm{aB}$ \\
\hline \hline
\end{tabular}

Médias seguidas por letras distintas, minúscula na vertical e maiúscula na horizontal, diferem entre si pelo teste de Duncan ao nivel de $1 \%$ de probabilidade. 
Este resultado também foi obtido por PEREIRA et al. (1983), em experimento onde testou o enraizamento, com ANA a 2000 ppm na forma liquida, de diferentes tipos de estacas de goiabeira da cultivar Paluma. $O$ tratamento com as estacas herbáceas resultaram em $70 \%$ de enraizamento, enquanto que as lenhosas, apenas $33 \%$.

Em outro trabalho, PEREIRA et al. (1991) testando o enraizamento de estacas herbáceas de cultivares de goiabeira com AIB no mês de novembro, obtiveram um número médio de raízes para a Rica $21,62 \%$ e para Paluma, 29,03\%. KERSTEN \& IBAÑEZ (1993), quando trabalharam com a cultivar Kumagai utilizando as concentraçбos de 0, 2000, 3000,4000 e 5000 ppm de AIB, observaram uma maior tendência de enraizamento em estacas da posiçăo apical. Entretanto, a diferença significativa encontrada foi entre estacas da posição mediana e apical nas concentraços de AIB. Os autores também encontraram maior teor de aminoácidos totais em estacas da posição apical de ramos de goiabeira, o que possivelmente exerce influência sobre a formação de raizes.

$O$ efeito das concentrações de AIB, no enraizamento, ajusta-se a uma equação de regressão linear. Houve um aumento de estacas enraizadas com as concentrą̧̋̃es de AIB, conforme se pode observar na Figura 1.

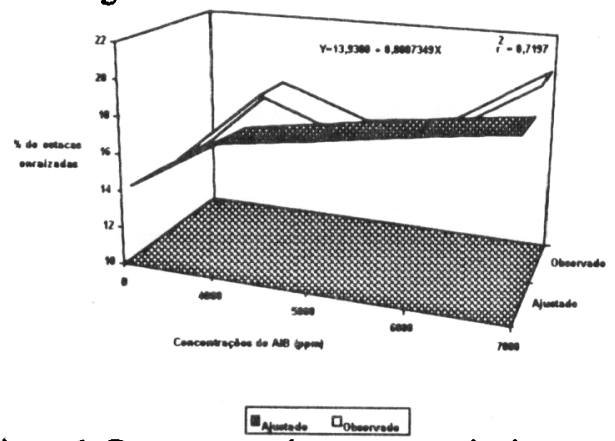

Figura 1. Percentagem de estacas enraizadas nas diferentes concentrações de AIB.
A respeito disto, VIJAY KUMAR \& CHAUHAN (1974) afirmam que a concentração adequada para o enraizamento de estacas de goiabeira, está entre 4000 e 8000 ppm de AIB. Já KERSTEN \& IBAN̂̃EZ (1993) obtiveram as maiores percentagens de enraizamento nas concentraçóes de 4000 e 5000 ppm de AIB.

O menor enraizamento obtido no tratamento sem AIB, em todas as épocas, indica influência do regulador sobre o enraizamento de estacas desta espécic. Esta foi também a constatação de GONZÁLEZ \& SCHIMIDT (1992), quando obtiveram $25 \%$ de enraizamento em estacas de goiabeira tratadas com $1000 \mathrm{ppm}$ de AIB e apenas 3,37\% para a testemunha. Segundo HARTMANN \& KESTER (1990), o estímulo ao enraizamento se dá até uma determinada concentração, a partir da qual o efeito passa a ser inibitório. Neste experimento não se observou efeito inibidor do regulador vegetal.

Possiveis efeitos nocivos do substrato, não foi constatado, visto o material utilizado ter apresentado, em teste de retenção, adequada manutençăo de umidade.

\section{Peso da matéria seca de raizes}

O peso da matéria seca das raízes apresentou influência significativa da época de estaquia, dos tratamentos com AIB e das interaçðes entre época e tipo de estaca e época e AIB.

Conforme se observa na TABELA 3, as estacas medianas tiveram maior peso de matéria seca de raizes do que as apicais. As estacas medianas tiveram formaçăo de raizes mais desenvolvidas, tanto em diâmetro quanto em comprimento, resultando então em maior peso de matéria seca. É provável que isto tenha ocorrido porque as estacas medianas da maioria das espécies possuem maiores teores de substâncias de reserva do que as apicais. Tais resultados coincidem com os de LIMA et al. (1992) em trabalho com estacas enfolhadas de acerola..

TABELA 3. Peso médio de matéria seca de raizes (g) dentro do fator tipo de estaca, nas diferentes épocas de estaquia

\begin{tabular}{lllll}
\hline \hline Tipo de Estaca & Epoca 1 & Epoca 2 & Epoca 3 & Epoca 4 \\
\hline medianas & $0,725 \mathrm{aA}$ & $0,017 \mathrm{aB}$ & $0.00 \mathrm{~B}$ & $0,110 \mathrm{aB}$ \\
apical & $0.351 \mathrm{bA}$ & $0.007 \mathrm{aB}$ & $0,00 \mathrm{~B}$ & $0,251 \mathrm{bA}$ \\
\hline \hline
\end{tabular}

Médias seguidas por letras distintas, minúscula na vertical e maiúscula na horizontal, diferem entre si pelo teste de Duncan ao nível de $1 \%$ de probabilidade. 
O tratamento com AIB foi significativo na época 1 e apresentou uma curva de regressão com tendência quadrática, Figura 2. A concentração de $4347 \mathrm{ppm}$ foi o ponto de máxima que originou a maior média de peso seco que foi de $0,65 \mathrm{~g}$.

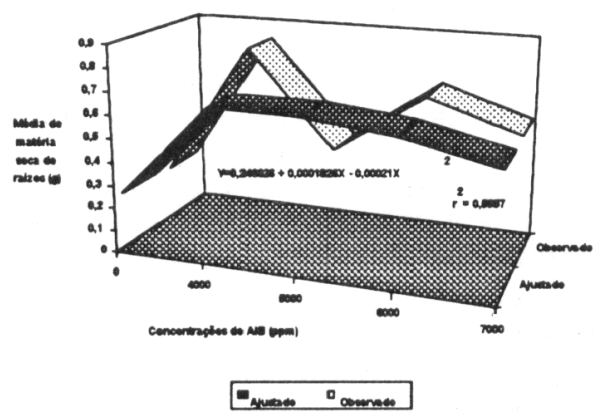

Figura 2. Peso médio de matéria seca de raízes em diferentes concentrações de AIB.

Sobre a influência do AIB sobre o tipo de raizes formadas, GALSTON \& DAVIES (1972), afirmam que o tratamento com auxinas podem modificar tanto o número quanto o tipo de raiz.

PEREIRA et al. (1991), testando o efeito do AIB no enraizamento de estacas herbáceas de dois cultivares de polpa vermelha de goiabeira, constataram que estacas tratadas com este regulador, mostraram precocidade na iniciação radicular e maior número e peso de raizes, indicando a eficiência da aplicação do regulador. Já GONZÁLEZ \& SCHMIDT (1992), em trabalho semelhante, com estacas de goiabeira, não encontraram diferença significativa ao nível de $5 \%$, nos parâmetros número, comprimento e peso seco de raízes em nenhum tratamento.

FACHINELLO et al. (1992), trabalhando com goiaba serrana, relatam que o AIB proporcionou maior número de estacas enraizadas e que estas apresentaram sistema radicular mais forte, com raízes maiores e melhor formadas.

\section{Percentagem de estacas que formaram calo}

Constatou-se que época, variedade e as interaçóes época e tipo de estaca, época e variedade, foram significativos na formação de calo.

Pode se observar na TABELA 4, que as estacas medianas tiveram maior formação de calos que as estacas apicais, possivelmente devido a estas possuirem maior concentração de substâncias endógenas promotoras de enraizamento (HARTMANN \& KESTER, 1990).

A interação variedade (cor de polpa) e época de estaquia, é apresentada na Tabela 5 onde verifica-se que a tendência para formar calos, foi bastante variável. Entretanto também dentro de variedade, a maior formação de calos ocorreu nas épocas em que houve menor formação de raizes. A variedade de polpa branca apresentou maior formação de calos somente na estaquia realizada em outubro.

TABELA 4. Percentagem média de calos dentro do fator tipo de estaca, nas diferentes épocas de estaquia

\begin{tabular}{lllll}
\hline \hline Tipo de Estaca & Época 1 & Época 2 & Época 3 & Época 4 \\
\hline mediana & $1,43 \mathrm{aC}$ & $47,47 \mathrm{aA}$ & $20,44 \mathrm{aB}$ & $24,54 \mathrm{aB}$ \\
apical & $5,82 \mathrm{bC}$ & $27,18 \mathrm{bA}$ & $15,78 \mathrm{aB}$ & $21,63 \mathrm{aA}$ \\
\hline
\end{tabular}

Médias seguidas por letras distintas, minúscula na vertical e maiúscula na horizontal, diferem entre si pelo teste de Duncan ao nível de $5 \%$ de probabilidade.

TABELA 5. Percentagem média de calos dentro do fator variedade, nas diferentes épocas de estaquia.

\begin{tabular}{lllll}
\hline \hline Variedade & Época 1 & Época 2 & Época 3 & Época 4 \\
\hline polpa vermelha & $1,51 \mathrm{aD}$ & $50,78 \mathrm{aA}$ & $31,64 \mathrm{aB}$ & $19,44 \mathrm{aC}$ \\
polpa branca & $5,66 \mathrm{bC}$ & $24,28 \mathrm{bA}$ & $7,65 \mathrm{bB}$ & $26,91 \mathrm{aA}$ \\
\hline \hline
\end{tabular}

Médias seguidas por letras distintas, minúscula na vertical e maiúscula na horizontal, diferem entre si pelo teste de Duncan ao nivel de $5 \%$ de probabilidade. 
Não houve efeito significativo do tratamento com AIB, sobre a formação de calos, entretanto a concentração de $6000 \mathrm{ppm}$ foi a que mais apresentou formação de calos.

GONZÁLES \& SCHMMIDT (1992) utilizando 0,1000 e 2000 ppm de IBA, em estaquia realizada em março, obtiveram para cultivar Kumagai alta percentagem de calo (71\%), no tratamento controle.

O menor valor de calos observado, ocorreu na época de estaquia fevereiro (Figura 3), contrariamente ao que ocorreu para enraizamento das estacas. Conforme HARTMANN \& KESTER (1990) frequentemente as raizes aparecem após a formação de calos, através de uma diferenciação das células parenquimatosas formadoras deste.

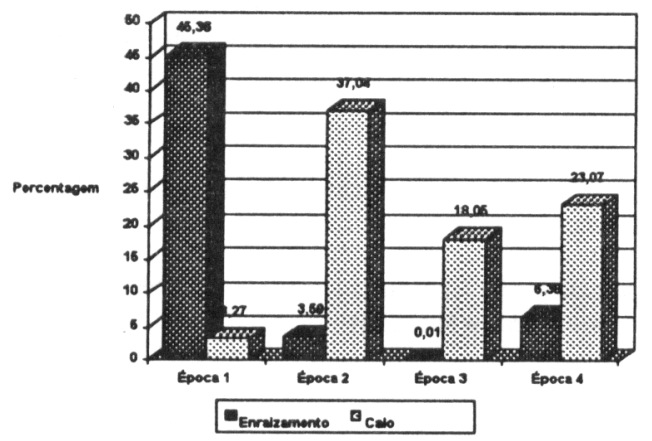

Figura 3. Percentagem média de estacas enraizadas e de estacas com calo, nas respectivas épocas de estaquia.
Mas dependendo das condições ambientais e das condições internas na estaca, como presença de cofatores, a formação da raiz pode se dar diretamente sem desenvolvimento de calo ou formar calo em maior ou menor espaço de tempo. Provavelmente, a temperatura acelerou o processo de enraizamento na época 1, atrasando nas demais onde se obteve maior percentagem de estacas com calo do que com raiz. Nas épocas onde o enraizamento foi muito baixo as estacas, na sua maioria, ñ̃o morreram, isto é evidenciado pelo alto número de calos. Possivelmente, com exceção da época de estaquia fevereiro, nas demais é necessário um maior periodo de tempo para que ocorra formação de raizes em estacas de goiabeira.

\section{Percentagem de estacas brotadas}

Época, tipo de estaca, variedade e suas interaçбes foram significativas pelo teste $F$.

A interação entre época e tipo de estaca é apresentada na TABELA 6, onde verifica-se a superioridade da emissão de brotos das estaca medianas em relação às apicais. Este comportamento, provavelmente, também é devido a maior quantidade de substâncias de reserva contido nas estacas medianas.

$\mathrm{Na}$ interação época e variedade, as estacas da variedade de polpa vermelha, resultaram em maior quantidade de estacas brotadas do que as da variedade de polpa branca, exceto na época 4 (outubro), igualmente ao que ocorreu no enraizamento (TABELA 7).

TABELA 6. Percentagem média de brotações dentro do fator tipo de estaca, nas diferentes épocas de estaquia.

\begin{tabular}{lllll}
\hline \hline Tipo de estaca & Epoca 1 & Epoca 2 & Epoca 3 & Epoca 4 \\
\hline mediana & $10,65 \mathrm{aD}$ & $26,72 \mathrm{aB}$ & $46,85 \mathrm{aA}$ & $17,88 \mathrm{aC}$ \\
apical & $3,35 \mathrm{bC}$ & $18,15 \mathrm{bD}$ & $38,14 \mathrm{bA}$ & $23,53 \mathrm{aB}$ \\
\hline \hline
\end{tabular}

Médias seguidas por letras distintas, minúscula na vertical e maiúscula na horizontal, diferem entre si pelo teste de Duncan ao nível de $5 \%$ de probabilidade.

TABELA 7. Percentagem média de brotaçбes dentro do fator variedade nas diferentes épocas de estaquia.

\begin{tabular}{lllll}
\hline \hline Variedade & Epoca 1 & Epoca 2 & Época 3 & Epoca 4 \\
\hline polpa vermelha & $10,83 \mathrm{aC}$ & $27,50 \mathrm{aB}$ & $49,12 \mathrm{aA}$ & $14,59 \mathrm{aC}$ \\
polpa branca & $3,25 \mathrm{bC}$ & $17,48 \mathrm{bB}$ & $35,96 \mathrm{bA}$ & $27,42 \mathrm{bA}$ \\
\hline \hline
\end{tabular}

Médias seguidas por letras distintas, minúscula na vertical e maiúscula na horizontal, diferem entre si pelo teste de Duncan ao nivel de $5 \%$ de probabilidade. 
PEREIRA et al. (1991) constataram que estacas das cultivaras Rica e Paluma, ambas de polpa vermelha não diferiram quanto as estacas brotadas aos 180 dias.

O comportamento contraditório entre formação de raizes e emissão de brotos (Figura 4) ou formação de gemas talvez possa ser explicado pelo conteúdo de constituintes da planta como adeninas, cinetinas e auxinas.

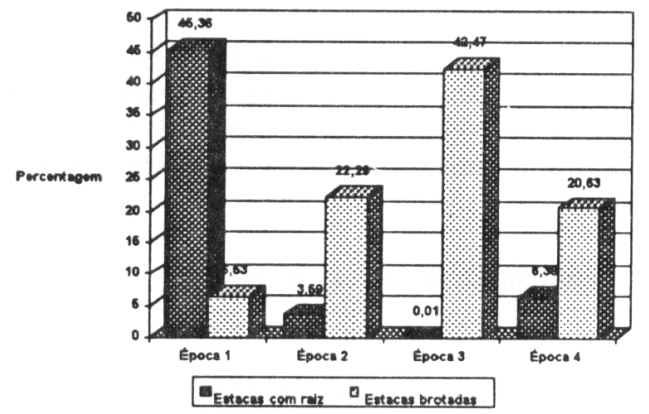

Figura 4. Percentagem média de estacas enraizadas e de estacas brotadas, nas respectivas épocas de estaquia.

KERSTEN (1987) relata ter sido demonstrado que, quando a concentração de auxinas é relativamente alta ocorre um favorecimento na formação de raizes adventícias, impedindo a formação de gemas. Mas quando as cinetinas e adeninas encontram-se em níveis altos, acontece a formação de gemas e há emissão de brotações, inibindo a formação de raizes. HARTMANN \& KESTER (1990) afirmam que a capacidade de enraizamento de estacas de algumas espécies pode ser alterada por eliminação de gemas, pois há uma relação entre enraizamento e número de gemas nos ramos.

PEREIRA et al. (1983) encontraram resultados de brotação, analisados aos 60 dias, com a mesma tendência de crescer à medida que decrescia a de enraizamento. Entretanto os dados não permitiram correlacionar as variáveis, parecendo que a brotação não interferiu na de enraizamento.

A formação de brotaçðes parece estar associada principalmente com a sobrevivência, não implicando, porém, no seu enraizamento pelo menos para o periodo estudado neste trabalho. Os tratamentos com regulador AIB não tiveram efeito sobre o desenvolvimento das brotaçzes nas estacas.

\section{CONCLUSÕES}

a) a época de estaquia da goiabeira, influencia significativamente as percentagens de estacas enraizadas, com calo, brotadas e peso de matéria seca de raizes;

b) a maior percentagem de estacas enraizadas ocorre com a estaquia em fevereiro:

c) estacas apicais são as que apresentam maior percentagem de enraizamento;

d) o ácido indolbutírico (AIB), aumenta significativamente o enraizamento de estacas e o peso de matéria seca de raizes;

e) o AIB é menos efetivo nas estaquias realizadas em julho e em outubro;

f) a variedade de polpa vermelha, foi superior quanto as percentagens de estacas enraizadas, com calos e brotadas nas estaquias realizadas em fevereıro, abril e julho;

\section{REFERÊNCIAS BIBLIOGRÁFICAS}

ANUÁRIO ESTÁTISTICO DO BRASIL - 1991, Rio de Janeiro, v 51, p. 505, 1991.

CAVALCANTE, AL. Agricultor produz goiaba para fazer $e$ vender doces. Manchete Rural, Rio de Janeiro,n 80, p. 46-49, 1993.

FACHINELLO, J.C.; MIELKE, M.S.; NACHTIGAL, J.C. Propagação vegetativa da goiabeira serrana (Feyoa sellowiana Berg.). Revista Brasileira de Fruticultura, Cruz das Almas, v.14, n.3, p. 233-236, 1992.

FIGUEIREDO, S.L.B. Efeito do estiolamento parcial e do scido ndolbutírico (AIB) no enralzamento de estacas de ramos de golabeira serrana (Feijoa sellowiana, Berg.). Pelotas, 1993. 71p. Dissertação (Mestrado)- Faculdade de Agronomia "Eliseu Maciel", Universidade Federal de Pelotas.

GALSTON, A.W.; DAVIES, P.J. Mecanismos de controle no desenvolvimento vezetal. Să Paulo: Edgar de Blucher, $1972.171 \mathrm{p}$.

GONZAGA NETO, L.; SOARES, J.M. Goiaba para expotaçâ: aspectos técnicos da produção. Brasília: EMBRAPA, SPI, 1994. $49 \mathrm{p}$.

GONZÁLEZ, M.G.N.; SCHIMIDT, C.A.P. Estudo do efeito de duas concentraçðes de ácido indolbutírico (AIB) e ácido naftaleno acético (ANA) no enraizamento de esta. cas herbáceas de goiabeira (Psıdıum guajava L.) cv. Kumagai. Revista Brasileira de Fruticultura, Cruz das Almas, v.14, n.3, p.229-232, 1992. 
HAMILTON, R.A.; SEAGRAVE-SMITH, H. Growing guava for processing. Honolulu: University of Hawaii, 1954. 12 p. (Extension Bulletin, 63).

HANSEN, J. Influence of position and temperature during rooting on adventitious root formation and axilary bud break of Stephanotis floribunda. Scientia Horticulturae, Amsterdam, v. 40, p. 345-354, 1989.

HANSON, C.K. The effects of indobutyric acid on rooting Lovell and Nemaguard peach cuttings. HortSclence, Saint Joseph , v.13, n.3, p.374, 1978.

HARTMANN, H.T.; KESTER, D.E. Propagacion de plantas: principios y practicas. México: Ed Continental, 1990. 760p.

KERSTEN, E. Propagação vegetativa dos citros por métodos não convencionais. Piracicaba: ESALQ, 1987. 20 p.

KERSTEN, E.; IBAÑEZ, U.A. Efeito do ácido indolbutírico (IBA) no enraizamento de estacas de ramos de goiabeira (Psidium guajava L.) em condiçăo de nebulização e teor de aminoácidos totais. Revista Brasileira de Fruticultura, Cruz das Almas, v.15, n.1, p.87-89, 1993.

LIMA, A.C.S.; ALMEIDA, F.A.C.; ALMEIDA F.C.G. Estudo sobre o enraizamento de estacas de acerola (Malphigia glabra L.). Revista Brasileira de Fruticultura, Cruz das Almas, v.14, n.1, p.7-13, 1992.
MEDINA, J.C. Cultura In: INSTITUTO DE TECNOLOGIA DE ALIMENTOS Goiaba: cultura, matéria-prima, processamento e aspectos econômicos.Campinas, 1988. cap. 1, p. 1-120. (ITAL. Frutas Tropicais, 6).

NACHTIGAL, J.C. Propagação de araçazeiro (Psıdium cattleyanum Sabine) através de estacas semilenhosas. Pelotas, 1994. 73 p. Dissertação (Mestrado)-Faculdade de Agronomia "Eliseu Maciel", Universidade Federal de Pelotas.

PEREIRA, F.M.; OIOLI, A.A.P.; BANZATO, D.A. Enraizamento de diferentes tipos de estacas enfolhadas de goiabeira (Psıdium guajava L.) em câmaras de nebulização. Científica, São Paulo, v.11, n.2, p.239-244, 1983.

PEREIRA, F.M.; PETRECHEN, E.H.; BENINCASA, M.M.P.; BANZATTO, D.A. Efeito do ácido indolbutírico no enraizamento de estacas herbáceas de goiabeira (Psidium guajava, L.) das cultivares "Rica" e"Paluma", em câmara de nebulização. Científica, São Paulo, v.19, n.2, p.199-206, 1991.

VIJAY KUMAR, N.; CHAUHAN, K.S. Studies on the role of auxins, inibitors, and root promoting co-factors in rooting stem cuttings of guava (Psidium guajava L.). In: INTERNATIONAL HORTICULTURAL CONGRESS, 19., Warszawa, 1974. Proceedings. Warszawa: The International Society for Horticultural Science, 1974, p.482.

Recebido para publicação em 15.02 .95

Aceito para publicação em 28.08.95 